\title{
Aggressive behavior and extinction-induced response-rate increase'
}

\author{
TRAVIS THOMPSON AND WILLIAM BLOOM
}

UNIVERSITY OF MINNESOTA

Discontinuing positive reinforcement has been shown to elicit fighting in hooded rats, and to be associated with a transitory increase in the vigor and rate of the previously reinforced operant. The present study shows that the tendency for response frequency to increase and the tendency to attack covary following extinction-onset. It is also shown that, as the augmented response rate decreases, the tendency to attack diminishes and that the former change precedes the latter change.

Withholding positive reinforcement after a history of reinforcement contingent on emission of an operant is associated with a transitory increase in response rate, force and duration (Notterman, 1959; Margulies, 1960). Azrin, Hutchinson, \& Hake (1965) found that pigeons subjected to brief extinction periods would attack a stuffed dummy of a pigeon mounted on a switch in the test chamber. The specific relation between such extinction-induced attack and increased response rate and duration is, however, not clear.

Previous studies by Thompson $(1961,1962)$ and Thompson, Heistad, \& Palermo (1963) have dealt with changes in response rate and duration of operants during extinction. The purpose of the present research was to examine the covariation between the duration of fighting and the tendency for response rate to increase following extinction onset. In addition, the changes in both variables as a consequence of repeated exposure to nonreinforcement were explored. In this method, fooddeprived rats were conditioned on a regular foodreinforcement schedule. A satiated animal was subsequently introduced into the test chamber along with the food-deprived animal, and training sessions were continued until the presence of the satiated animal had no discernible effect on the stability of lever-pressing performance. Then a series of extinction and reconditioning sessions were run, and response-frequency changes and the duration of fighting were recorded. Progressive changes in fighting and extinction-induced rate increase were examined over a series of successive extinctions and reconditioning sessions.

Subjects. Two male hooded rats, weighing 380 and $360 \mathrm{gm}$ respectively, served as experimental Ss, and two additional male hooded rats, weighing 355 and $345 \mathrm{gm}$ respectively, served as objects of attack during extinction periods.

Apparatus. A Foringer rat test chamber, equipped with a microswitch lever, a feeder, house lights, and an exhaust fan, served as the experimental apparatus. The test chamber was connected with relay-timer switching apparatus which arranged reinforcement and extinction contingencies, and recorded responses. The animals were fed Purina Fox Chow in their home cages and received 45-mg Noyes rat pellets in the experimental situation. The test chambers were situated in a room adjacent to the programming and recording equipment, providing some sound attenuation.

Procedure. The rats were systematically deprived of food until their weights dropped to $80 \%$ of their free-feeding weights. They were magazine trained for two 1-hr. sessions, then placed on a regular reinforcement schedule (CRF). Conditioning sessions were run until the response rate over a $15-\mathrm{min}$. session was stable. Then a foodsatiated rat was placed in the test chamber along with the trained, food-deprived animal. Conditioning was continued until the cumulative records over a $15-\mathrm{min}$. session were stable.

A standard series of sessions was run in which 50 reinforcements were followed by $5 \mathrm{~min}$. of extinction, followed by another 100 reinforcements. The duration of fighting was recorded by visually observing the two animals in the test chamber and closing the leaf on a hand-operated microswitch during fighting and releasing it during non-fighting periods. This method is similar to one described by Ulrich \& Azrin (1962) who recorded frequency of fighting this way. The inter-observer agreement varied from $83 \%$ to $100 \%$ of the total fighting duration per session. The number of lever-pressing responses and the total duration of fighting behavior during the period preceding the onset of extinction were recorded, and the same variables were recorded during successive minutes of the $5-\min$. extinction period. Thus, the rate of lever pressing and mean duration of fighting before extinction onset were calculated as control levels, and leverpressing rate and duration of fighting per minute during extinction were recorded as deviations from this base line.

Lever-pressing reconditioning was run for 100 reinforcements after the $5-\mathrm{min}$, extinction period, when lever pressing usually returned to the base-line rate and fighting diminished to nearly $0 \mathrm{sec}$. This procedure was replicated on five successive sessions for each animal. Then five additional sessions were run on which all responses were reinforced ( 150 reinforcements), followed by another series of five extinction and reacquisition sessions. The procedure during the second series of extinction sessions was identical with the first, and comprised a replication and additional measure of progressive change in extinction-induced response-rate increase and aggressive

\section{Results and Discussion}

For the first few sessions following introduction of the satiated animal, lever pressing was intermittently disrupted by social interaction between the two animals. These periods rapidly diminished, then virtually disappeared. The satiated animals tended to remain on the side of the box opposite the food hopper, while the fooddeprived animals occupied the side near the lever and hopper. During the first extinction session both of the satiated animals suffered lacerations on the back and neck. Such obvious damage did not occur on subsequent extinctions, although vocalization and what appeared to be biting about the neck and back continued to occur. It was not possible to specify a single topography of fighting which occurred on all occasions, although sequences closely resembling those presented in Figs. 30 and 31 in Barnett (1963) were most commonly observed. 2

Figure 1 presents records of the number of lever presses per minute before the beginning of extinction and of the number of lever presses per each minute of extinction in the ten extinction sessions. In addition, the 


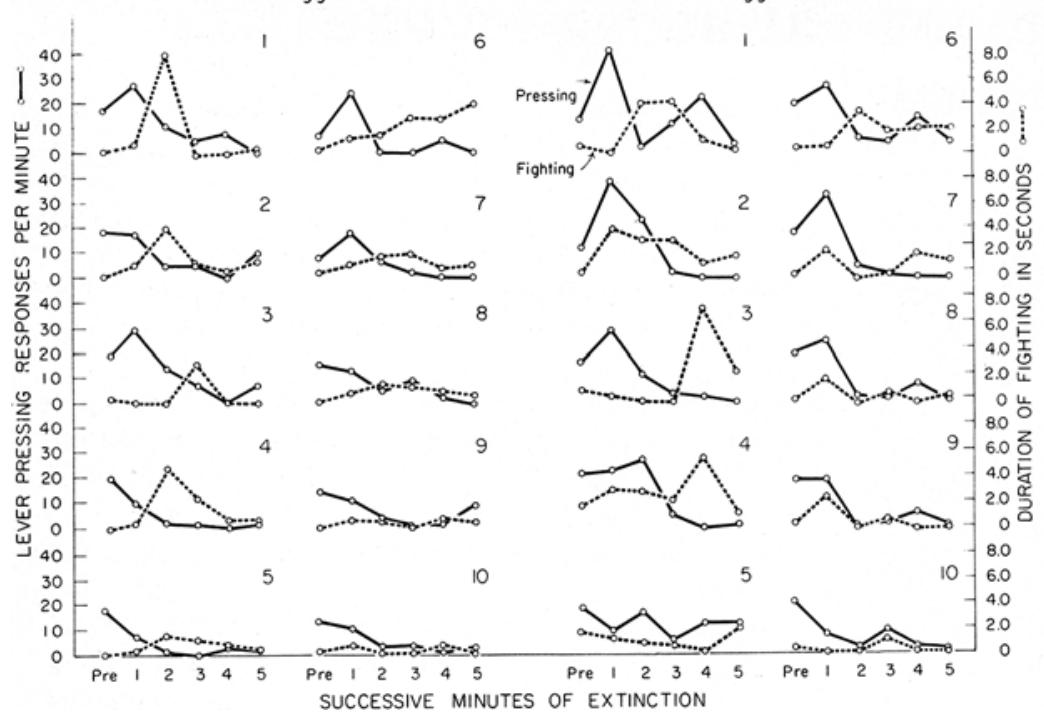

Fig. 1. Concurrent record of lever pressing responses and fighting duration before and during five minutes of extinction on ten extinction sessions. A period of reconditioning on CRF was interspersed between the first $(1-5)$ and second (6-10) set of extinction sessions for both subjects ( 344 and 341 ),

total duration of fighting per minute is plotted concurrently, permitting direct comparisons of the temporal relations between the two behavioral measures. The magnitude of the rate increase was greatest during the first minute of extinction, diminishing over each 5-min. extinction period. This was true during both the first and second series of extinction sessions. It is also noteworthy that on the first two extinction sessions, the duration of fighting increased from nearly 0 sec. per minute prior to extinction onset, to 6-8 sec.during each of the first 2 min. of extinction. The greatest increase in lever-pressing rate occurred during the first minute of extinction, while increased fighting was greatest during the second or third minute of extinction. As with lever-pressing rate, the duration of the fighting decreased over successive extinction sessions, until it had returned nearly to the base-line duration by the fifth extinction period.

During the second extinction series the absolute magnitude of both response rate-increase and duration of aggressive interaction were less than during the first series, and they returned to base line more rapidly. Thus, the previous exposure to non-reinforcement affected subsequent response to extinction.

These data indicate that not only does discontinuing positive reinforcement increase the probability of occurrence of aggressive behavior as reported by Azrin, Hutchinson, \& Hake (1965), but that there is a systematic relation between the increase in the rate of the previously reinforced response and the tendency for fighting to occur. The covariation of these two variables is apparent over successive exposures to non-reinforcement, as well as within a given session. The temporal relation between the two suggests that the previously reinforced operant has an initially higher probability of occurrence but that this is followed by an increased tendency for aggressive behavior.

\section{References}

Azrin, N. H., Hutchinson, R. R., \& Hake, D. F. Extinction-induced aggression. Amer. Psychologist, 1965, 20, 583.

Barnett, S. A. The rat: $A$ study in behaviour. Chicago: Aldine Publishing Co., 1963. P. 88.

Margulies, S. Response duration in operant level, regular reinforcement, and extinction. J. exp. Anal. Behav., 1961, 4, 317-322.

Notterman, J. M. Force emission during bar pressing. J. exp. Psychol., 1959, 58, 341-347.

Thompson, T. Effects of chlorpromazine on "aggressive" responding in the rat. $J$. comp. physiol. Psychol., 1961, 54, 398-400.

Thompson, T. The effect of two phenothiazines and a barbiturate on extinction-induced rate increase of a free operant. $J$. comp. physiol. Psychol., 1962, 55, 714-718.

Thompson, T., Heistad, G. T., \& Palermo, D. S. Effect of amount of training on rate and duration of responding during extinction. J. exp. Anal. Behav., 1963, 6, 155-161.

Ulrich, R. E., \& Azrin, N. H. Reflexive fighting in response to aversive stimulation. J. exp. Anal. Behav., 1962, 5, 511-520.

\section{Notes}

1. This research was supported in part by research grant GB 1912 from the National Science Foundation.

2. Previous unpublished studies with this procedure using SpragueDawley albino rats failed to produce reliable fighting of this type. Azrin has made a similar observation (personal communication). 